\section{Repercusiones de la pandemia COVID-19 en los ingresos y egresos económicos del odontólogo general}

\section{Impact of the COVID 19 pandemic on the economic income and expenses of the general dentist}

\section{Resumen}

Objetivo. Conocer las opiniones de los odontólogos peruanos respecto a las repercusiones que ha tenido la pandemia COVID-19 en sus ingresos y egresos económicos. Métodos. Estudio cualitativo con enfoque fenomenográfico que utilizó la técnica de la entrevista a profundidad dirigida a siete odontólogos en el contexto de la pandemia durante el mes de mayo del 2020 en Lima (Perú). Las entrevistas se desarrollaron de forma virtual y las categorías incluyeron: rentabilidad del ejercicio de la atención odontológica; perspectiva con respecto al ingreso de la atención odontológica en los periodos de aislamiento social y reinserción de las actividades de rutina. Resultados. Los odontólogos entrevistados perciben que durante este periodo se ha reducido los ingresos en la atención odontológica, ya sea por las medidas de restricción social instauradas en el Perú, además de la baja rentabilidad de los tratamientos de urgencia y emergencia dental. Por ello, la viabilidad de la atención odontológica durante el periodo de aislamiento social se ha visto perjudicada tanto en el aumento del presupuesto convencional para brindar el servicio y los egresos adicionales que se estiman para cumplir con los lineamientos sanitarios para el retorno de las actividades laborales. Conclusiones. Se percibe una disminución de los ingresos económicos en la atención odontológica, además de un aumento de los egresos económicos durante los periodos de aislamiento social y reinserción a las actividades laborales de rutina.

Palabras clave: Atención odontológica; Salud bucal; COVID-19; Coronavirus; Estatus económico (fuente: DeCS BIREME).

\footnotetext{
Abstract

Objective. To determine the opinions of Peruvian dentists regarding the impact of the COVID- 19 pandemic on their income and expenses. Methods. Qualitative study with a phenomenographic focus that used the technique of in-depth interviews with seven dentists in the context of the pandemic during the month of May 2020 in Lima (Peru). The interviews were conducted virtually and the categories included: cost-effectiveness of
}

\section{Artículo Original}

Giancarlo Pares-Ballasco ${ }^{1,}$ a , Yuri Castro-Rodríguez ${ }^{1, b}$

1 Universidad Nacional Mayor de San Marcos, Sociedad Científica de Estudiantes de Odontología, Lima, Perú.

${ }^{a}$ Estudiante del pregrado.

${ }^{\mathrm{b}}$ Magíster en Educación.

\section{Correspondencia:}

Jesús Giancarlo Pares-Ballasco: jesuspares19@hotmail.com Mz.E lote 20 comité 3. Palermo. Lima, Perú.

ORCID: 0000-0001-9589-8033

\section{Coautor:}

Yuri Castro Rodríguez: yuricastro_16@hotmail.com ORCID: 0000-0002-9587-520X

\section{Editora:}

Antonieta Pérez-Flores

Universidad de Concepción, Chile.

Conflicto de intereses: los autores declaran no tener conflicto de intereses.

Fuente de financiamiento: financiado por los autores.

Recibido: 25/08/20

Aceptado: 14/09/20

Publicado: $16 / 11 / 20$

(C) Los autores. Este artículo es publicado por la revista Odontología Sanmarquina de la Facultad de Odontología, Universidad Nacional Mayor de San Marcos. Este es un artículo de acceso abierto, distribuido bajo los términos de la licencia Creative Commons Atribucion - No Comercia_Compartir Igual 4.0 Internacional. (http://creativecommons.org/licenses/by-nc-sa/4.0/) que permite el uso no comercial, distribución y reproducción en cualquier medio, siempre que la obra original sea debidamente citada. 
dental care delivery; perspective on dental care productivity during periods of social isolation and reintegration into routine activities. Results. The dentists interviewed perceive that during this period there has been a reduction in income from dental care delivery, either because of the measures of social restriction established in Peru, or because of the low profitability of emergency and urgent dental treatment. For this reason, the viability of dental care during the period of social isolation has been affected by both, the increase in the conventional budget to provide the service and the additional expenses to comply with new healthcare providers' guidelines. Conclusions. A decrease in economic income is perceived in dental care, in addition to an increase in economic expenditures during periods of social isolation and reinsertion into routine work activities.

Keywords: Dental care; Oral health; COVID-19; Coronavirus; Status economic (source: MeSH NLM).

\section{Introducción}

Los primeros casos de COVID-19 fueron registrados en diciembre de 2019 en la ciudad de Wuhan, China y, desde ese momento, ha tenido una desmesurada propagación por los países del mundo. Por ello, el 11 de marzo de 2020 la Organización Mundial de Salud (OMS) caracteriza al COVID-19 como una pandemia ${ }^{1}$. Bajo este contexto, las actividades odontológicas y actividades médicas particulares han sido limitadas considerablemente (se ha reducido la atención, los costos de la atención y servicios se han incrementado, los insumos han elevado sus precios, se ha reducido el personal asistencial de apoyo), por ello surgen nuevos desafíos tanto en el ejercicio laboral asistencial como en los ingresos y egresos económicos del odontólogo, gerente y personal asistencial $^{2}$.

La actividad odontológica de rutina ha sido limitada a solo tratamientos de urgencia y emergencia dental durante la pandemia ${ }^{3}$. Es importante que el cirujano dentista que brinde este servicio cumpla con nuevas medidas de bioseguridad implementadas por distintas instituciones, gobiernos y sociedades científicas ${ }^{4,5}$. Además, las restricciones sociales implementadas por varios países como medidas de prevención y una mayor demanda percibida de equipos de bioseguridad para dar abasto al sector de salud y población nos llevan a plantearnos si es viable la práctica dental durante este contexto.

Entidades representativas de la salud bucal se han hecho la misma pregunta y se ha analizado la realidad vivida por muchos cirujanos dentistas en diversos países durante la pandemia. $\mathrm{Al}$ respecto, estudios realizados por la Asociación Dental Americana (ADA), Asociación Dental Irlandesa, Consejo General de Dentistas y la Asociación Dental Británica han descrito una realidad condicionada a la adquisición de equipos de protección personal, los cuales se perciben con un mayor costo o son escasos; la disminución de los ingresos en la atención odontológica; lo poco rentable que es ejercer la práctica odontológica bajo este contexto y la estimación de un futuro no prometedor para la actividad clínica privada ${ }^{6-9}$.

En el contexto peruano, el primer caso de COVID-19 es reportado un 6 de marzo de 2020. Esto generó que el gobierno peruano tome medidas de prevención para poder contener la propagación de este virus, por ello el 15 de marzo de 2020 se instaura en el Perú el aislamiento social ${ }^{10,11}$. Los meses de marzo, abril y mayo han sido periodos caracterizados por el distanciamiento físico entre las personas en las calles, horarios restringidos para transitar, un aumento progresivo del número de contagiados y un sistema de salud colapsado que marcan un precedente de cambio en el servicio odontológico.

No es la primera vez que la atención odontológica lidia con problemas de salud laboral, anteriormente se tenía en cuenta a la hepatitis B y hepatitis $\mathrm{C}^{12}$. No obstante, el contexto vivido amerita la modificación de los protocolos de bioseguridad usados convencionalmente y una nueva estimación de los costos para brindar el servicio odontológico. Es necesario la implementación de ciertas modificaciones en la clínica dental durante esta etapa de crisis, además de replantearse volver a ejercer la atención odontológica para el caso de los dentistas que tengan su actividad suspendida. Todo ello se realizará en un contexto ajeno a lo que normalmente se percibía como un ingreso y un panorama distinto al presupuesto de inversión considerado.

Por otro lado, las respuestas de otros países frente al cese de las actividades laborales han beneficiado a la actividad odontológica. Tal es el caso de Irlanda que otorga préstamos financieros de $5000 €$ a $50,000 €$ a cirujanos dentistas con el objetivo de compensar las pérdidas producidas por la pandemia ${ }^{7,13}$. Además, en Canadá se les da un beneficio de $847 \$$ por semana a los dentistas que laboren dentro de una empresa dental afectada. ${ }^{14}$ En el contexto peruano se ha buscado apoyar a las pequeñas y medianas empresas; no obstante, es necesario indagar si los odontólogos peruanos se han beneficiado con estas iniciativas ministeriales. Ello implicaría un resalte en la idea de invertir y lidiar con los gastos durante y después del periodo de aislamiento social, además de la estimación de los ingresos.

Por todo lo anteriormente descrito es necesario conocer ¿Cuáles son las repercusiones que ha tenido la pandemia COVID-19 en los ingresos y egresos económicos del cirujano dentista? ¿Qué estrategias se encuentran realizando estos cirujanos dentistas para revertir los costos de servicios que han dejado de realizarse? ¿Qué reajustes se realizarán a los tratamientos convencionales y aquellos 
que requieran los servicios de laboratorios dentales? De esta forma en el presente estudio se tuvo como objetivo describir cómo perciben los cirujanos dentistas peruanos la repercusión de la pandemia COVID-19 en sus ingresos y egresos económicos.

\section{Métodos}

El presente estudio pertenece a una investigación cualitativa del tipo descriptiva, que utilizó la fenomenografía como enfoque metodológico ${ }^{15-17}$. Se utilizó la técnica de la entrevista a profundidad donde participaron siete odontólogos peruanos con diferentes años de experiencia laboral, grado académico y especialidades.

Se realizaron dos sesiones virtuales en las cuales no se tomaron en cuenta las diferencias mencionadas anteriormente para su participación. Además, los profesionales fueron informados que para ser partícipes de este estudio debían de cumplir por lo menos con uno de los siguientes criterios: haber estimado el aspecto económico para ejercer la atención de urgencia y emergencia dental; brindar servicios de urgencia y emergencia dental durante la pandemia, y considerar reactivar su atención odontológica en el periodo de reinserción a las actividades sociales. La mayoría de los participantes cumplió con más de uno de los criterios mencionados anteriormente. Se incluyó a estos participantes con el objetivo de tener una mejor recopilación de información y esta sea fructífera al desarrollo del estudio.

Los odontólogos fueron contactados por medio de redes sociales (debido al aislamiento social instaurado por el gobierno peruano como medida de prevención frente a la pandemia, por ello no se pudo realizar las entrevistas de manera presencial) para informarles, a cada uno de ellos, de las condiciones de participación, presentación e información del proyecto y fecha de realización de las entrevistas. A todos los participantes se les envió una ficha de recolección de datos para conocer sus datos sociodemográficos tales como: años de experiencia laboral, situación actual de su atención odontológica, estudios de posgrado, lugar donde labora. El primer grupo contó con la participación de cuatro odontólogos (1 mujer y 3 varones) y el segundo grupo, con la participación de tres odontólogos (1 mujer y 2 varones) (Tabla1).

Las entrevistas virtuales se llevaron a cabo a mediados del mes de mayo del 2020 (el periodo de aislamiento social empezó el 15 de marzo del presente año). En éstas se plantearon una serie de preguntas ordenadas en cinco grupos (Tabla 2). Cada grupo de preguntas contuvo una categoría que fue el punto de discusión; no obstante, los grupos de preguntas no fueron excluyentes de categorías, sino buscaron recopilar más información desarrollando su tópico de discusión. Las entrevistas se realizaron mediante la plataforma virtual Zoom (servicio de videoconferencia que permite hacer reuniones interactivas mediante el uso de video y audio). Al iniciar la reunión, previamente acordado con los participantes, se explicó cómo se llevaría a cabo el desarrollo de la sesión, el objetivo y las consideraciones éticas. Luego, se les informó a los participantes que la sesión sería grabada, por ello requerimos su consentimiento verbal; no obstante,

Tabla 1. Características sociodemográficas y laborales de los odontólogos participantes

\begin{tabular}{|c|c|c|c|c|c|}
\hline $\begin{array}{l}\text { Código de } \\
\text { participante }\end{array}$ & Estudios de posgrado & $\begin{array}{l}\text { Años de experiencia } \\
\text { laboral }\end{array}$ & $\begin{array}{l}\text { Principal cargo } \\
\text { que ocupa }\end{array}$ & $\begin{array}{l}\text { Lugar principal donde } \\
\text { labora }\end{array}$ & $\begin{array}{l}\text { Situación actual de su atención } \\
\text { odontológica }\end{array}$ \\
\hline Od.1 & $\begin{array}{l}\text { Diplomado, } \\
\text { maestría, doctorado, } \\
\text { segunda especialización }\end{array}$ & 30 & $\begin{array}{l}\text { Gerente general / } \\
\text { director }\end{array}$ & Lince & Suspendida \\
\hline Od.2 & $\begin{array}{l}\text { Diplomado, } \\
\text { maestría, doctorado, } \\
\text { Segunda especialización, } \\
\text { Lic. en Derecho y Cien- } \\
\text { cias Políticas }\end{array}$ & 25 & $\begin{array}{l}\text { Gerente general / } \\
\text { director }\end{array}$ & $\begin{array}{l}\text { Lince, La Molina, San } \\
\text { Juan de Lurigancho, } \\
\text { San Martin, San Isidro } \\
\text { (Lima) }\end{array}$ & $\begin{array}{l}\text { Restringida a solo tratamien- } \\
\text { tos de urgencia y emergencia } \\
\text { dental. }\end{array}$ \\
\hline Od.3 & $\begin{array}{l}\text { Diplomado, maestría, } \\
\text { segunda especialización } \\
\text { (sin sustentar) }\end{array}$ & 16 & $\begin{array}{l}\text { Gerente general / } \\
\text { director }\end{array}$ & Los Olivos (Lima) & $\begin{array}{l}\text { Restringida a solo tratamien- } \\
\text { tos de urgencia y emergencia } \\
\text { dental. }\end{array}$ \\
\hline Od.4 & Maestría & 8 & $\begin{array}{l}\text { Gerente general / } \\
\text { director }\end{array}$ & $\begin{array}{l}\text { Los Olivos } \\
\text { (Lima) }\end{array}$ & suspendida \\
\hline Od.5 & $\begin{array}{l}\text { Cursos de extensión } \\
\text { universitaria }\end{array}$ & 3 & $\begin{array}{l}\text { Subgerente / } \\
\text { subdirector }\end{array}$ & $\begin{array}{l}\text { Moyobamba, Chacha- } \\
\text { poyas (San Martín) }\end{array}$ & $\begin{array}{l}\text { Restringida a solo tratamien- } \\
\text { tos de urgencia y emergencia } \\
\text { dental. }\end{array}$ \\
\hline Od.6 & $\begin{array}{l}\text { Diplomado, } \\
\text { maestría, } \\
\text { segunda especialización, } \\
\text { cursos de extensión } \\
\text { universitaria }\end{array}$ & 15 & $\begin{array}{l}\text { Personal } \\
\text { especialista }\end{array}$ & $\begin{array}{l}\text { San Luis } \\
\text { (Lima) }\end{array}$ & suspendida \\
\hline Od.7 & Diplomado & 4 & $\begin{array}{l}\text { Gerente general / } \\
\text { director }\end{array}$ & $\begin{array}{l}\text { Lima, Villa El Salvador } \\
\text { (Lima) }\end{array}$ & $\begin{array}{l}\text { Restringida a solo tratamien- } \\
\text { tos de urgencia y emergencia } \\
\text { dental. }\end{array}$ \\
\hline
\end{tabular}


Tabla 2. Grupos de preguntas para las entrevistas virtuales vía Zoom

\begin{tabular}{|c|c|}
\hline Número de grupo & Preguntas \\
\hline I & $\begin{array}{l}\text { - De los ingresos económicos percibidos de manera normal en la atención odontológica antes de la pandemia } \\
\text { COVID-19 ¿Cuáles serían los motivos de la disminución de los ingresos económicos en la práctica dental } \\
\text { durante la pandemia? } \\
\text { - ¿Qué consecuencias de índole económica implicaría el cese total de la atención odontológica? }\end{array}$ \\
\hline II & $\begin{array}{l}\text { - ¿Qué consideraciones serían fuentes de ingreso en la atención odontológica que compensen un posible déficit } \\
\text { - } \quad \text { ¿Es rente este periodo? } \\
\text { - qué? } \\
\text { - ¿Ha recibido apoyo financiero por parte del estado u otra institución durante la pandemia? } \\
\text { ¿Es probable que la atención odontológica regrese a los niveles de servicio o acceso pre pandemia después de } \\
\text { la crisis? ¿por qué? }\end{array}$ \\
\hline III & $\begin{array}{l}\text { - ¿Considera adecuado elevar los precios de la atención de tratamientos de urgencia y emergencia dental } \\
\text { durante la pandemia? ¿por qué? } \\
\text { ¿Considera adecuado elevar los precios de la atención odontológica de rutina después de terminado el perio- } \\
\text { do de aislamiento social? ¿por qué? }\end{array}$ \\
\hline IV & $\begin{array}{l}\text { - ¿Qué opina acerca de la adquisición de equipos de protección personal (mascarilla facial, guantes, mandiles } \\
\text { - } \quad \text { Adesechables, etc.) durante la pandemia COVID- 19? ¿cómo cree que afectará sus egresos económicos? } \\
\text { - ¿Es posible que solicite un préstamo financiero para el mantenimiento de su clínica dental durante la pande- } \\
\text { - } \quad \text { iQué futuros gastos se tendrían en cuenta para volver a ejercer la práctica dental de rutina? }\end{array}$ \\
\hline V & - ¿Tiene algo más que comentar? \\
\hline
\end{tabular}

se indicó que si había alguna disconformidad podían abandonar la reunión.

Ambas sesiones estuvieron dirigidas por un mismo investigador, el cual realizó las preguntas a cada participante en orden aleatorio, es decir un participante respondía el primer grupo de preguntas seguido cualquier otro participante respondía el mismo grupo de preguntas hasta terminar con ese grupo y de nuevo de forma aleatoria responder el siguiente grupo.

Las categorías de las preguntas incluyeron: conocimiento del contexto actual de la atención odontológica, opinión sobre la rentabilidad del ejercicio de la atención odontológica restringida a tratamientos de urgencia y emergencia dental, opinión sobre los motivos que disminuyen, mantienen y generan ingresos económicos durante pandemia, opinión sobre los motivos que disminuyen, mantienen y generan ingresos económicos en el periodo de reinserción a las actividades sociales, opinión sobre la modificación de los precios a propósito de la pandemia COVID-19 y opinión sobre los egresos económicos en la atención odontológica a propósito de la pandemia COVID-19. Las entrevistas duraron 3 horas y fueron grabadas con el consentimiento de los participantes. Al finalizar las entrevistas se dieron las conclusiones finales por parte de los investigadores y agradecimientos a cada uno de los participantes.

Para el análisis de datos se transcribieron las entrevistas de forma textual colocando un código a cada participante para su reconocimiento. Una vez transcrita toda información brindada por los participantes se identificaron las categorías y subcategorías relacionadas al tema de estudio. Se compararon las respuestas de cada participante de forma interpretativa.

\section{Resultados}

Las entrevistas grupales desarrollaron temas en torno a las consideraciones de los ingresos y egresos económicos a propósito de la pandemia COVID-19. Se discutieron aspectos como las consideraciones de la disminución del ingreso económico percibido en la atención odontología a propósito de la pandemia COVID-19, consideraciones que mantienen y generan los ingresos económicos en la atención odontológica a propósito de la pandemia COVID-19; consideraciones de los egresos económicos durante los periodos de aislamiento social y reinserción a las actividades sociales y consideraciones del precio de la atención odontológica en tiempos del COVID-19.

Consideraciones de la disminución del ingreso económico percibido en la atención odontológica a propósito de pandemia COVID-19. Seis participantes consideran que los ingresos en la atención odontológica durante los periodos de aislamiento social y reinserción a las actividades sociales tendrían cambios considerables. Actualmente, la actividad clínica privada de cuatro participantes se encuentra limitada a solo brindar tratamientos de urgencia y emergencia dental. Motivo de asumir las medidas de prevención recomendadas por la OMS y la ADA. Además, tres odontólogos acotaron que sus actividades se encontraban suspendidas temporalmente, pero tenían en mente la reactivación de sus servicios conforme se aclare el panorama.

Od.3: "Siendo la profesión odontológica quien tiene un mayor riesgo potencial de contagio y posibilidad de desarrollo de focos de infección. Se nos recomendó prestar solo servicios de urgencia y emergencias dental". 
Od.6: "Pretendo salir a atender cuando se levante la cuarentena. Primero con los pacientes que han quedado con tratamientos inconclusos, pues son los más interesados a que se les vuelva a atender y luego seguir con las atenciones de urgencias".

Los participantes tenían a su disposición cierta cantidad semanal de pacientes, previo a la instauración de las restricciones sociales, para los cuales el servicio brindado era diario o interdiario. Una vez establecido el estado de emergencia, los odontólogos entrevistados informaron que una de las consideraciones de la disminución de los ingresos económicos en la actividad odontológico es la disminución de pacientes en la clínica. Esto debido a diversos motivos como la escasa movilización de la población, el miedo a contagiarse durante el transcurso a la clínica, no considerar una prioridad la atención odontológica bajo este contexto y el miedo a un posible contagio dentro del consultorio odontológico. Cabe resaltar que la realidad descrita se situó en los dos primeros meses de aislamiento social (meses de abril a mayo) en el Perú.

Od.4: "Generalmente tengo pacientes que no tienen un sueldo fijo y es por eso que, bajo este contexto, el paciente prefiere gastar su dinero en alimentos de primera necesidad".

Od.5: "Los casos de COVID-19 están en aumento, todavia no hay una histeria colectiva de contagio ante la exposición al salir, pero si se manifiesta en un grupo reducido de la población".

Od.6: "Existe la posibilidad de que los precios incrementen en la consulta y que los pacientes consideren que sea una necesidad no tan importante... priorizando otras como su alimentación".

Otra consideración expresada por cinco de los participantes es la limitación de las actividades odontológicas a solo tratamientos de urgencia y emergencia dental. Las razones puntuales mencionadas por los entrevistados que ejercen la práctica en este contexto son la baja rentabilidad que estas tiene en comparación con la atención odontológica de rutina; el ejercicio de esta actividad restringida involucra dejar un periodo de ventilación en el consultorio de 3 a 4 horas, por ello la cantidad de pacientes atendidos por día es limitado; las urgencias son pocas y las emergencias, mucho menos. $\mathrm{Al}$ respecto, otro participante acotó que, si bien el ingreso percibido no era el mismo, el suspender totalmente nuestra actividad generaría un golpe mayor en nuestros ingresos. Los tratamientos de urgencia no son rentables, pero el mismo hecho de mantener el ejercicio durante este periodo está permitiendo regular flujo el dinero.

Od.3: "Nos encontramos en un proceso de transición o suspensión, por ello de disminución de los ingresos económicos percibidos. Estamos en espera de un nuevo protocolo de manejo de infecciones en la clínica dental para el virus COVID-19".

Od.5: "Se está atendiendo con algunas limitaciones los tratamientos de urgencias... con un par de ho- ras de separación entre pacientes para poder realizar la desinfección del ambiente de manera adecuada y evitar el riesgo a la exposición".

Od.6: "Las emergencias como tal no se deben atender en consultorios, sino en hospitales... el solamente atender urgencias no generarian muchos ingresos... ni, aunque el consultorio se dedique esencialmente a la atención odontológica con dolor dental".

Od.7: "He estado atendiendo urgencias dentales y los ingresos que se percibian de manera regular, se han visto mermados de un $100 \%$ a un $20 \%$ aproximadamente".

Es importante tener en consideración la paralización de los vuelos interprovinciales, ya que algunos odontólogos que brindaban sus servicios en distintas partes del país, por días particulares, se han visto perjudicados destacó un participante. Además, los despidos temporales del personal odontológico que perciben un sueldo por honorarios, bajo este contexto, se han visto obligados a suspender sus actividades, según dos de los participantes. Esta situación nos ha afectado a todos, pero se debe recalcar que a unos más que a otro.

Od.4: "El cierre total de los consultorios implicaría una mayor tasa desempleo para los dentistas que trabajan por un porcentaje o los que cuentan con un consultorio independiente".

Od.5: "Particularmente traía un ortodoncista de Lima que venía una vez al mes. Por la paralización de vuelos ha dejado de venir. Los pacientes se han quedado sin control y solo nos hemos dedicado a cambio de ligas en pacientes que necesitan control".

Od.7: "En mi caso también tengo un especialista que hace endodoncias, el cual no está asistiendo al consultorio".

Consideraciones que mantienen y generan los ingresos económicos en la atención odontológica a propósito de la pandemia COVID-19. Respecto a las consideraciones que mantienen y generan ingresos económicos, las opiniones de nuestros participantes fueron variadas. Tres de los participantes afirmaron que una adecuada planificación y organización de nuestros servicios nos permitirá desarrollar mejores propuestas de valor frente al desarrollo del COVID-19. Estamos en un momento difícil, por ello es necesario conocer cómo hemos estado trabajando, cuál ha sido nuestro nivel de administración, cuáles han sido nuestros ingresos y egresos económicos y quiénes son nuestros pacientes. A partir de ello, establecer una propuesta de mejora que sobre todo alcance al paciente y desarrolle nuestros servicios odontológicos, destacó un participante. Además, el análisis de fortalezas, oportunidades, debilidades y amenazas (FODA) debemos de aplicarlo en el lugar donde laboremos, ya que ello nos dará un panorama de las fortalezas, oportunidades y amenazas que se pueden presentar durante la pandemia COVID-19.

Od.1: "Los impuestos, la baja de pacientes y no tener una organización puede afectar a nuestro negocio". 
Od.3: "Debemos hacer una autoevaluación clinica y académica para cuantificar que modificaciones se deben de hacer y tener una mejor planificación con respecto a la atención odontológica".

Otra consideración destacada, a propósito de la pandemia COVID-19, por tres de los participantes fue la teleodontología como una opción para mantener la comunicación con los pacientes, observar si es necesario que el paciente acuda a consulta y orientarlo en temas de salud bucal. De esta manera, el paciente percibe la calidad humana del odontólogo por mitigar su necesidad, bajo este contexto.

Od.3: "De esta forma pude atender a cuatro pacientes a nivel nacional y 10 pacientes a nivel local. Si bien es cierto que no les cobré por el servicio brindado, el hecho de atenderlos es una forma de cuidarlos y sé que ellos serán mis futuros pacientes, además de que recomendarán mis servicios".

Od.5: "Como una medida preventiva a la exposición desmesurada, muchos pacientes están prefiriendo realizar la teleconsulta".

Od.6: "Para los pacientes que solo quieran preguntar, la teleconsulta sería una herramienta muy útil, incluso el tema de cobrar o no una tele consulta debería ser considerado".

Por otro lado, cuatro de los participantes consideran a la formalización de sus servicios odontológicos como una fuente de ingresos, a propósito de la pandemia, que ha disminuido de cierta manera sus egresos, ya que por medio de resoluciones ministeriales las pequeñas y medianas empresas han recibido beneficios con el objetivo de mantener al personal y posteriormente estos puedan reincorporarse a sus actividades.

Od. 2: "El estado ha cubierto un porcentaje de mi planilla de trabajadores"

Od.3: "Tenemos que ser formales y tener una licencia de funcionamiento, además de categorizar nuestro servicio en Registro Nacional de Instituciones Prestadoras de Servicios de Salud (RENIPRESS). Hoy en día el gobierno está brindando ayuda mediante el programa Reactiva Perú".

Od.6: "He recibido apoyo financiero por medio de una disposición en la cual todos los trabajadores que estaban en planilla recibirian un apoyo de 370 soles (3,50 soles $=1$ dólar $) "$

Cabe resaltar la opinión de un participante que acotó con respecto al tema de los ingresos en la atención de urgencias dentales. Paradójicamente, en la situación que está viviendo, ha recibido una mayor cantidad de pacientes nuevos en estos dos meses de atención con restricciones sociales. Por la forma como se está dando la atención se debe de aprovechar las oportunidades que se presenten, por ello mientras los pacientes vean un buen servicio y se sientan seguros dentro de tu consultorio te van a recomendar.
Otro participante expresó que frente a una crisis siempre existirán oportunidades, ya que en nuestra profesión debemos de tener en consideración la existencia de la oferta y la demanda. Tenemos una gran demanda en la atención odontológica, ya sea las caries, enfermedad periodontal y mal oclusión que son las tres enfermedades con mayor prevalencia e incidencia en la población. Esa demanda tiene que irse a un lado y una vez que termine la condición en la que estamos debemos de saber captarla. La tarea de esta etapa es prepararnos para el periodo en el que se permita brindar nuevamente nuestra actividad odontológica de rutina.

Od.1: "Debemos estar preparados para recibir a un nuevo mercado. Quien logre adaptarse mejor en el tiempo menor posible será el que coseche las ganancias de la demanda".

Por otro lado, tres participantes consideraron como una fuente de ingresos adicional a la atención odontológica, no muy lejana a nuestro rubro, la venta de materiales de desinfección usados en el consultorio, la venta de elementos de protección personal y aparatos nuevos para el control de los aerosoles.

Od.7: "Como una forma de compensar la disminución de mis ingresos me estoy dedicando a la venta de equipos de bioseguridad".

Consideraciones de los egresos económicos durante los periodos de aislamiento social y reinserción a las actividades sociales. En lo que refiere a los gastos e inversiones en la atención odontológica durante este periodo, los participantes comentan diversos aspectos por considerar. La principal consideración mencionada por cuatro de los participantes es invertir en una atención odontológica de alta calidad enfocada en el paciente, además de cumplir con los parámetros de las autoridades de control para que nos permitan ejercer nuestra profesión durante el periodo de reinserción de las actividades laborales. El paciente se sentirá a gusto y tendrá la plena confianza de asistir a los centros odontológicos.

Od1: "La Superintendencia Nacional de Fiscalización Laboral (SUNAFIL) y la Superintendencia Nacional de Salud (SUSALUD) harán que los consultorios cumplan con ciertos niveles de calidad para que estos puedan ser autorizados y brinden sus servicios".

Od.7: "Nos toca estar constantemente informados sobre este virus para tomar todas las precauciones del caso, evitar descuidarnos en la protección personal y brindar un buen servicio a los pacientes".

Otra consideración destacada por todos los participantes son las modificaciones que se llevaran a cabo en el ejercicio profesional a propósito de la pandemia. La implementación de los equipos de protección personal en un nuevo flujograma de actividades que va desde la programación de citas, esterilización de los instrumentales, desinfección del ambiente y en la atención odontológica tanto para el operador como el paciente; la revaluación de los pagos del personal que labora en tu consultorio o 
clínica; evaluar si contamos con los equipos de esterilización recomendados, además de tener a nuestra disposición instrumental y equipos odontológicos autorizados por las entidades de salud dental para reducir el riesgo de contagio. Cabe resalta la opinión de un participante con respecto a la evaluación de nuestro espacio laboral, ya que se recomienda que nuestro ambiente cuente con ventilación.

O1: "Tenemos que prepararnos para tener una práctica odontológica de rutina teniendo en cuentas las adaptaciones que se tendrán en un futuro próximo".

O3: "Hay que invertir en modificar muchas cosas dentro del consultorio odontológico, ya sea desde los elementos de protección personal, instalar un esterilizador autoclave, el sistema de alta succión, el aire acondiciona debe ser direccionado hacia una posición y se debe tener tres a cuatro piezas de alta velocidad para su uso alternativo".

O4: "Si trabajamos en un lugar pequeño que no cuente con una ventilación adecuada nos exponemos a desarrollar un foco de infección. Se debe de ventilar el consultorio entre 3 a 4 horas. Para los que cuentan con más de una unidad deberían crear ambientes separados con ventanas para una mejor ventilación".

\section{O7: "Implicaría una renovación completa de toda nuestra organización en el consultorio".}

Una consideración mencionada por cinco de los participantes es el incremento del precio de los elementos de protección personal a raíz de una mayor demanda percibida durante la pandemia. Si bien su uso es necesario para evitar el desarrollo de focos de infección en nuestros servicios no hay que desestimar que la inversión que se dé excede a los costos fijos anteriormente previstos.

Od.3: "El incremento del precio de los materiales de protección se ha quintuplicado".

Od.5: "El aumento del costo es bárbaro. Una caja de mascarilla que te costaba entre 6 a 7 soles y por cantidad a 5 soles, pues ahora la misma caja te está costando entre 180 a 200 soles. $(3,50$ soles $=$ 1 dólar)"

Od.7: "Los equipos de bioseguridad que debemos de adquirir como las mascarillas, mandilones y guantes se han incrementado en un 70 a $100 \%$ su precio".

No solamente es el precio de los equipos de protección personal, sino también debe considerarse el precio de los materiales usados en nuestra actividad profesional durante la pandemia. La limitación de los medios de transporte con respecto a la importación de materiales de uso odontológico sería un inconveniente en el desarrollo de nuestro ejercicio profesional, ya que la mayoría de estos provienen del extranjero, recalcaron dos participantes. Además, otro participante acotó que la variación del dólar también tendría cierta influencia en el precio de los insumos dentales.
Od. 7: "En cuanto a los materiales en Lima, la mayoría son de importación. El proveedor que traía los materiales ha subido el precio de las anestesias".

Por otro lado, el profesional debe saber si nuestra organización tiene socios claves o personas que intervienen con nosotros para la producción de nuestros servicios. Los servicios odontológicos normalmente cuentan con empresas que se encargan del recojo de sus residuos y como consecuencia de este contexto se aumentarán los costos de sus servicios, ya que sus protocolos de atención no serán los mismos. Además, el servicio de limpieza dentro de la clínica o consultorio será mucho más exhaustivo destacó otro participante.

Desde otro punto de vista, tres participantes comentaron que generalmente los que se dedican a la práctica independiente tienen compromisos con entidades bancarias desde antes de empezar la pandemia. Lidiar con estos egresos y no percibir el mismo ingreso es una consideración a tener en cuenta; no obstante, en este contexto las pequeñas y medianas empresas han recibido beneficios por medio de resoluciones ministeriales como préstamos financieros con bajas tasas interés y beneficios tributarios.

Od.1:" Tal vez este sea el único momento donde el hecho de ser una empresa formal te permita acceder a un préstamo con una tasa de interés baja, además las empresas formales recibirán beneficios tributarios".

Od.4: "Se pueden solicitar préstamos con una baja tasa de interés".

Od.7: "Las entidades bancarias nos han dado financiamiento de 24 a 36 meses, pero al no percibir ingresos mensuales, pues eso ajusta un poco nuestro presupuesto".

Otra consideración indicada por un participante es que se deba de invertir en un profesional administrativo que nos ayude con la estructura de costo, la administración de los recursos y nos enseñe un poco de cultura financiera, porque estos puntos son los que repercuten finalmente en nuestra práctica. Ello debe ser una inversión futura y no, ser visto como un gasto, ya que nos facilitará la planificación del proceso y te permitirá tener ingresos adicionales.

Consideraciones respecto al precio de la atención odontológica en tiempos del COVID-19. Con respecto a la elevación del precio, nuestros participantes manifestaron dos puntos:

Cuatro participantes consideraron que es importante mantener los precios durante la pandemia. Hay que tener en consideración los términos urgencia y emergencia, ya que no solo hablamos de una condición, sino de nuestros pacientes. Por ello, es importante preservar la relación con nuestros pacientes antiguos en consideración al contexto que nos ha tocado vivir. Para los pacientes nuevos se harán algunos ajustes. Además, un participante de este grupo destacó que, ante un tratamiento de alta calidad, se establezcan precios que sean 
razonables y rentables, ya que servirá para poder mantener la viabilidad del ejercicio profesional. El cirujano dentista que tenga un servicio de atención debe saber acerca de su estructura de costos para estimar cuanto es lo que va a costar brindar su servicio a la durante los periodos de aislamiento social y reinserción a las actividades laborales.

Od.1: "La evaluación de la estructura de costos nos ayudará a tener una idea clara de cuanto está costando producir 30 minutos de consulta. Si no sabemos cuáles son los costos fijos o costos variables será difícil tomar una decisión en la parte financiera".

Por otro lado, tres participantes consideraron que es un hecho el aumento del precio de los tratamientos de urgencia y emergencia dental, además de considerar que el precio de la atención odontológica de rutina, también, se deba elevar. Los motivos serían una mayor inversión en equipos de bioseguridad, ya que como medida de prevención debe usarlo el odontólogo, asistente dental, personal de recepción y paciente, el aumento del precio de los equipos de protección personal, la adquisición de equipos de esterilización recomendados, una mayor inversión en materiales de desinfección y las futuras inversiones que se realicen con el objetivo de cumplir todas las medidas preventivas del caso. El COVID-19 va a marcar un hito en el tema de la atención odontológica, así como lo fue el VIH en su momento.

Od.7: "Mis precios por tratamientos de urgencia ya los he incrementado casi todos. He incrementado el precio de mis consultas y después de la pandemia sí pienso subir los precios de algunos tratamientos".

Od.5: He aumentado el precio de mi consulta durante esta etapa. Antes de citar al paciente se le explica los procedimientos, el protocolo a tratar cuando llegue y al final se le dice el costo de la consulta. Casi un 100\% acepta y viene solo por la consulta.

Od.6: Hay una inversión extra con el incremento de los costos fijos que van a tener los odontólogos. En definitiva, se va a elevar los precios de la atención de rutina y se tendrá en cuenta al paciente para que esta decisión sea razonable.

\section{Discusión}

En el presente estudio se describieron las repercusiones de la pandemia COVID-19 en los ingresos y egresos económicos según la opinión de cirujanos dentistas con diferentes años de experiencia laboral y grado académico, además de ejercer la actividad clínica privada.

La pandemia COVID-19 no solo representa un gran problema de salud a nivel mundial, también, ha desequilibrado la economía de distintos países, reducido las actividades laborales, aumentado la tasa de desempleo y ha creado una mayor demanda en la canasta básica familiar ${ }^{18}$. El ámbito hospitalario no se ha visto exento de estás repercusiones, pues al enfocar su atención, en hacerle frente a esta enfermedad, ha obtenido pérdidas financieras, además de percibir un aumento en su estructura de costos ${ }^{19}$. Siendo así, los profesionales de la salud se han visto expuestos ante esta situación e inclusive, ha llevado a algunos a suspender sus actividades.

Bajo este contexto, la actividad odontológica no ha sido la única profesión de la salud que se ha visto afectada por el desarrollo de la pandemia COVID-19. Tal es el caso de los radiólogos quienes han limitado sus actividades y debido a las medidas de restricciones sociales han disminuido su demanda en análisis radiográficos ajenos al caso COVID-19 ${ }^{20}$. Además, las actividades médicas ambulatorias, en lo que respecta a sus actividades, comparten el mismo panorama ${ }^{21}$. Al respecto, la Odontología hoy en día es considerada una de las profesiones que presenta mayor riesgo de contagio ante esta pandemia ${ }^{22}$. Ello radica en las condiciones propias de acto estomatológico que de no ser abordadas con las medidas de bioseguridad adecuadas podrían incurrir en el desarrollo de infecciones cruzadas ${ }^{4,5,23}$. Por ello se considera que esta pandemia modificará diversos aspectos del servicio de odontológico que incluye la forma en cómo se brinde los servicios, el costo que involucra brindar dicho servicio y la valoración que este debe de tener.

Siendo así, la atención odontológica de nuestros participantes se encuentra en contextos distintos: la suspensión temporal de sus actividades o el ejercicio de su actividad restringida. La atención dental durante la pandemia debe seguir lineamentos estrictos avalados por las autoridades sanitarias, además de valerse de algunas herramientas como la teleodontología para el seguimiento y evaluación del tratamiento del paciente ${ }^{24}$. Estas modificaciones no solo radican en la implementación de un nuevo flujograma de actividades para el equipo de bioseguridad, también, se involucran cambios como el uso antiséptico para reducir la carga viral oral, el uso de radiografías panorámicas, alternativas apropiadas de equipos de esterilización, contar con instrumentales que no generen aerosoles, el tiempo de atención y periodo de desinfección, el uso de eyectores de saliva de alto volumen para disminuir el riesgo de contagio entre otros 23,25,26 Ello implica que para mantener la viabilidad de la atención odontológica durante la pandemia se deba realizar una mayor inversión, lo cual es una nueva estructura de costos que difiere al capital previsto anteriormente.

Frente a esta situación, los participantes de este estudio, que ejercen sus actividades durante este periodo mencionan que sus ingresos percibidos han disminuido, además de percibir un futuro aumento en sus costos fijos y variables. Se destacó, también, las opciones de poder recibir préstamos con bajas tasas de interés o, cierto apoyo por parte de Colegio Odontológico del Perú; sin embargo, ninguno de los participantes ha manifestado necesitarlo. Al respecto, estudios realizados por la Asociación Dental Irlandesa, Consejo General de Dentistas y la Asociación Dental Británica mediante el uso de encuestas virtuales obtienen resultados similares a nuestro estudio ${ }^{7-9}$.

Además, algunos de los participantes acotaron la situación del dentista que percibe ingresos por honorarios, los cuales estaban con despidos temporales; no obstante, 
el personal odontológico que forma parte de la planilla ha percibido cierto porcentaje de su sueldo por iniciativo ministerial, además se destaca la posibilidad de poder recibir préstamos con bajas tasas de interés o cierto apoyo por parte de Colegio Odontológico del Perú. En relación, estudios realizados por el Instituto de Políticas de Salud describe que el servicio odontológico se está recuperando conforme el paso del tiempo y que los dentistas empleados poco a poco estaban retomando sus actividades ${ }^{6}$. Cabe destacar, el seguimiento quincenal y el tamaño considerable de la muestra de dicho estudio, por ello puede ser considerado como un pronóstico positivo que se pueda dar en el contexto peruano.

Los participantes consideraron que deben hacerse reajustes en el precio de la atención odontológica a propósito de la pandemia COVID-19. Ello radica en que la atención odontológica, desde un enfoque empresarial, es transformada por el efecto del trabajo en un bien tangible con un valor agregado, el cual genera ganancias en base a un capital ${ }^{27}$. La modificación de la estructura de costos se verá plasmada en el aumento de los precios si es que este genera un déficit en la ganancia. En ese sentido, la odontología europea ha considerado elevar las tarifas dentales ${ }^{28}$. No obstante, se destaca que el paciente no es un cliente y que lo importante en el ejercicio de nuestra profesión es mantener la relación odontólogo- paciente, es decir que los servicios de salud no son objetos de comercialización, sino que está de por medio el beneficio del paciente ${ }^{29}$. En ese sentido, el reajuste de los precios debe tener una consideración empática con el paciente y de esta forma poder mantener la viabilidad del ejercicio profesional.

Por ello, la planificación y organización de nuestros servicios jugará un rol importante, por ello es necesario conocer ¿Cómo se ha estado brindando el servicio odontológico hasta la fecha? ¿Cuál ha sido el nivel de administración dentro de nuestros servicios? ¿Cuál han sido nuestros ingresos y egresos? ¿Quiénes acuden a nuestros servicios? Todo ello es básico de conocer para tener una reacción adecuada frente a la crisis. A partir de ello se establecerán propuestas de valor en consideración del paciente y desarrollo de los servicios odontológicos.

El presente estudio no está exento de limitaciones y podemos indicar que no se pudo contar con más odontólogos pertenecientes a diferentes especialidades para su participación en la entrevista vía online, debido a que no todos se conectaron o respondieron a la invitación enviada. Por lo que la cantidad de participantes fue pequeña; en consecuencia, los resultados deben ser interpretados de forma reservada sin generalizar. La entrevista online fue dependiente de la buena conectividad a la red por parte de todos los participantes que en algunas situaciones no se pudo controlar. Las entrevistas podrían ser reemplazadas de manera presencial para una mejor y directa comunicación con los participantes.

En el presente estudio se reportó las repercusiones de la pandemia COVID-19 en los ingresos y egresos económicos de la atención odontológica. Los cirujanos dentistas entrevistados han percibido una disminución de sus ingresos principalmente por la disminución de pacientes, la limitación de las actividades odontológicas y las medidas de restricción social instauradas por el estado peruano. Además, se percibe un aumento en los egresos económicos como consecuencia del aumento de los precios de elementos de protección personal y la implementación de modificaciones dentro del consultorio con el fin de cumplir las medidas sanitarias instauradas por las autoridades para brindar el servicio. En consecuencia, es muy probable un reajuste en los precios de la atención odontológica teniendo en cuenta la rentabilidad de nuestra propuesta de valor y el público a quien nos dirigimos.

\section{Referencias bibliográficas}

1. WHO. Virtual press conference on COVID-19. [citado 02/10/2020]. Disponible en: https://www.who.int/ docs/default-source/coronaviruse/transcripts/who-audio-emergencies-coronavirus-press-conference-fu1l-and-final-11 mar2020.pdf?sfvrsn=cb432bb3_2

2. Spagnuolo G, De Vito D, Rengo S, Tatullo M. COVID-19 Outbreak: An Overview on Dentistry. Int J Environ Res Public Health [Internet]. 2020 [citado 02/10/2020];17(6):2094. Disponible en: https://www. mdpi.com/1660-4601/17/6/2094

3. Coulthard P. Dentistry and coronavirus (COVID-19) moral decision-making. Br Dent J [Internet]. 2020 [citado 02/10/2020];228(7):503-5. Disponible en: https:// pubmed.ncbi.nlm.nih.gov/32277203/

4. Harrel S, Molinari J. Aerosols and splatter in dentistry: a brief review of the literature and infection control implications. J Am Dent Assoc [Internet]. 2004 [citado 02/10/2020];135(4):429-37. Disponible en: https:// jada.ada.org/article/S0002-8177(14)61227-7/abstract

5. Raghunath N, Meenakshi S, Sreeshyla HS, Priyanka N. Aerosols in Dental Practice- A Neglected Infectious Vector. BMRJ [Internet]. 2016 [citado 02/10/2020];14(2): 1-8. Disponible en: http://sciencedomain.org/abstract/14199

6. Irish Dental Association. Scale of Dental Collapse Highlighted in Survey. [citado 02/10/2020]. Disponible en: http://irishdentalassociation.newsweaver.com/newsletter/69fkfdpbrfc

7. British Dental Association. Practices weeks from collapse without rapid action from government. [citado 02/10/2020]. Disponible en: https://bda.org/news-centre/press-releases/practices-months-from-collapse-without-rapid-action-from-uk-government

8. General Advice of Dentists of Spain. El 10\% de los dentistas encuestados ha estado en contacto con el virus COVID-19 y el 2\% ha pasado la enfermedad. [citado 02/10/2020]. Disponible en: https://www.consejodentistas.es/comunicacion/actualidad-consejo/ notas-de-prensa-consejo/item/1767-el-10-de-los-dentistas-encuestados-ha-estado-en-contacto-con-el-virus-covid-19-y-el-2-ha-pasado-la-enfermedad.html

9. American Dental Association. COVID-19 Impact on Dental Practices - ADA Health Policy Institute. [citado 02/10/2020]. Disponible en: https://www.ada.org/en/ science-research/health-policy-institute/covid-19-dentists-economic-impact 
10. Maguiña C. Reflexiones sobre el COVID-19, el Colegio Médico del Perú y la Salud Pública. Acta Med Perú [Internet]. 2020 [citado 02/10/2020];37(1): 8-10. Disponible: doi: 10.35663/amp.2020.371.929 2 .

11. Chipana N, Espinoza C. COVID-19 y las Unidades de Cuidados Intensivos en el Perú. INTENSIVOS [Internet]. 2020 [citado 02/10/2020];13(1):40- 4. Disponible: doi: 10.37463/intens-samay/006

12. Moodley R, Naidoo S, Van Wyk J. The prevalence of occupational health-related problems in dentistry: A review of the literature. J Occup Health [Internet]. 2018 [citado 02/10/2020];60(2):111-25. Disponible en: https:// www.ncbi.nlm.nih.gov/pmc/articles/PMC5886878/

13. Microfinance Ireland. COVID-19 Business Loan. [citado 02/10/2020]. Disponible en: https://microfinanceireland.ie/loan-packages/covid19-2/

14. Canada.ca. Canada's COVID-19 Economic Response Plan. [citado 26/062020]. Disponible en: https://www. canada.ca/en/department-finance/economic-response-plan.html

15. Bowden J, Walsh E. Phenomenography. Australia: RMIT University Press;2000.

16. Barnard A, Mc Cosker H, Gerber R. Phenomenography: A Qualitative Research Approach for Exploring Understanding in Health Care. Qualitative Health Research. [Internet]. 1999 [citado 02/10/2020]; 9(2): 212-226. Disponible en: https://journals.sagepub.com/ doi/10.1177/104973299129121794

17. Richardson J. The concepts and methods of phenomenographic research. Review of Educational Research [Internet]. 1999 [citado 12/05/2020]; 69(1): 53-82. Disponible en: https://journals.sagepub.com/ doi/10.3102/00346543069001053\#articleCitationD ownloadContainer

18. Nicola M, Alsafi Z, Sohrabi C, Kerwan A, Al-Jabir A, Losifidis $\mathrm{C}$, et al. The socio-economic implications of the coronavirus pandemic (COVID-19): A review. Int J Surg [Internet]. 2020 [citado 02/10/2020]; 78:185-93. Disponible en: http://www.sciencedirect.com/science/ article/pii/S1743919120303162

19. Carroll N, Smith D. Financial Implications of the COVID-19 Epidemic for Hospitals: A Case Study. J Health Care Finance [Internet]. 2020 [citado 02/10/2020];46(4):12-20 Disponible en: http://www. healthfinancejournal.com/index.php/johcf/article/ view/216

20. Cavallo J, Forman H. The Economic Impact of the COVID-19 Pandemic on Radiology Practices. Radiology [Internet]. 2020 [citado 02/10/2020];201495. Disponible en: https://pubs.rsna.org/doi/10.1148/radiol.2020201495
21. Provenzano D, Sitzman B, Florentino S, Buterbaugh G. Clinical and economic strategies in outpatient medical care during the COVID-19 pandemic. Reg Anesth Pain Med [Internet]. 2020 [citado 02/10/2020]; 0:1-7. Disponible en: https://rapm.bmj.com/content/early/2020/05/31/rapm-2020-101640

22. Ather A, Patel B, Ruparel N, Diogenes A, Hargreaves KM. Coronavirus Disease 19 (COVID-19): Implications for Clinical Dental Care. J Endod [Internet]. 2020 [citado 02/10/2020]; Disponible en: http://www.sciencedirect.com/science/article/pii/S009923992030159X

23. Meng L, Hua F, Bian Z. Coronavirus Disease 2019 (COVID-19): Emerging and Future Challenges for Dental and Oral Medicine. J Dent Res [Internet]. 2020 [citado 02/10/2020];99(5):481-7. Disponible en: https://doi. org/10.1177/0022034520914246

24. Ge Z, Yang L, Xia J, Fu X, Zhang Y. Possible aerosol transmission of COVID-19 and special precautions in dentistry. J Zhejiang Univ-Sci B [Internet]. 2020 [citado 02/10/2020];21(5):361-8. Disponible en: https://doi. org/10.1631/jzus.B2010010

25. American Dental Association. ADA releases interim guidance on minimizing COVID-19 transmission risk when treating dental emergencies. [citado 02/10/2020]. Disponible en: https://www.ada.org/en/ publications/ada-news/2020-archive/april/ada-releases-interim-guidance-on-minimizing-covid-19-transmission-risk-when-treating-emergencies

26. Peng X, Xu X, Li Y, Cheng L, Zhou X, Ren B. Transmission routes of $2019-\mathrm{nCoV}$ and controls in dental practice. Int J Oral Sci [Internet]. 2020[citado 02/10/2020];12(9):1-6. Disponible en: https://www. nature.com/articles/s41368-020-0075-9

27. Gomes D, Souza F. El profesional de la odontología tras la reestructuración productiva: la ética, el mercado laboral y la salud pública dental. Saude soc. [Internet].2015[citado02/10/2020];24(1):285-297.Disponible en:http://www.scielo.br/scielo.php?script=sci_arttext\&pid=S0104-12902015000100285\&lng=en.

28. Consejo de dentistas.es. Resultados de la encuesta del Consejo Europeo de Dentistas (CED) sobre la situación de la Odontología europea en tiempos de COVID-19. [citado 02/10/2020]. Disponible en: https://www. consejodentistas.es/comunicacion/actualidad-consejo/ notas-de-prensa-consejo/item/1810-resultados-de-la-encuesta-del-consejo-europeo-de-dentistas-ced-sobre-la-situacion-de-la-odontologia-europea-en-tiempos-de-covid-19.html

29. Cabello E. Calidad de la Atención Medica: ¿Paciente o cliente? Rev Med Hered [Internet]. 2001[citado 02/10/2020]; 12(3):96-99. Disponible en: http:// www.scielo.org.pe/scielo.php?script=sci_arttext\&pi$\mathrm{d}=$ S1018-130X2001000300005\&lng=es. 